\title{
A EPILEPSIA COMO DOENCA INCAPACITANTE E OS CRITÉRIOS QUE IMPEDEM O ACESSO DOS EPILÉPTICOS AO AUXÍLIO-DOENÇA, À APOSENTADORIA POR INVALIDEZ E AO BENEFÍCIO DE PRESTAÇÃO CONTINUADA NO BRASIL.
}

\section{THE LABOR INCAPACITY AMONG THE EPILEPTICS AND THE CRITERIAS THAT PREVENTING EPILEPTICS TO ACCESS DISABILITIES PENSIONS IN BRAZIL.}

\author{
Lucas Aires Araújo 1
}

Igor de Andrade Barbosa ${ }^{2}$

\section{RESUMO}

De início, este artigo visa à apresentação dos direitos fundamentais contidos na Constituição Federal de 1988, com seus fundamentos e princípios. Posteriormente, passa-se ao estudo dos critérios para concessão dos benefícios previdenciários do tipo auxílio-doença e aposentadoria por invalidez - e mais o benefício de prestação continuada. Ao final, são apontadas lacunas no ordenamento jurídico brasileiro no que diz respeito ao pleno acesso do indivíduo epiléptico à Previdência Social e à Assistência Social, pois, por razão da ausência de dispensação de tratamento especial a estes deficientes, a rigidez dos critérios legais termina negando acesso a esses benefícios àqueles indivíduos que não se encaixam em todos os requisitos exigidos pela legislação. Ademais, ressalta-se que a conclusão deste trabalho é fruto de uma investigação científica baseada primordialmente em revisão da literatura específica e em consulta às leis brasileiras e às jurisprudências, com uma abordagem qualitativa.

PALAVRAS-CHAVE: Epilepsia. Direitos fundamentais. Incapacidade laborativa. Seguridade social.

\section{ABSTRACT}

At first, aiming to discover the criteria that prevent epileptics to access disabilities pensions in Brazil, the main purpose of this article is focused on the study of the legal requirements for granting social security benefits and social assistance benefits, as well

\footnotetext{
1 Discente do curso de Direito do Centro Universitário Católica do Tocantins - UniCatólica. E-mail: lucas.aires@a.catolica-to.edu.br. ORCID: https://orcid.org/0000-0002-6238-5749.

2 Mestre em Direito Econômico e Desenvolvimento pelo Programa de Mestrado em Direito da Universidade Candido Mendes - UCAM. Especialista em Relações de Consumo e em Direito da Concorrência e Propriedade Industrial, ambos pela UCAM. Defensor Público Federal de 1ำ categoria na Defensoria Pública da União do Tocantins e professor de graduação e pós-graduação do curso de Direito do Centro Universitário Católica do Tocantins - UniCatólica. E-mail: igor.barbosa@catolica-to.edu.br. ORCID https://orcid.org/0000-0001-6337-3873
} 
as present the principles of the fundamental rights contained in the Brazilian Federal Constitution. At the end, as a result of this investigation, is possible to realize that the mentioned benefits are not extended for all the epileptics who suffers from the inability to work. Thus, exist a potential violation to the Brazil Constitution's spirit, because does not exist a especial treatment for the epileptic population. Furthermore, this article was based primarily on a literature review, Brazilian laws and specifics case laws with a qualitative approach.

KEYWORDS: Epilepsy. Fundamental rigths. Labor disability. Social security.

\section{INTRODUÇÃO}

A Constituição da República Federativa do Brasil de 1988, nos seus primeiros títulos, positiva alguns direitos humanos, transformando-os em direitos fundamentais, prevendo, inclusive, garantias constitucionais para a efetivação dessas normas. Os direitos fundamentais são resultados de anos de lutas e movimentos sociais que, aos poucos, representaram mudanças de paradigmas sociais nos quais os direitos humanos ganharam cada vez mais destaques e os resultados foram sensíveis e progressivas mudanças nos ordenamentos jurídicos modernos. Parte da doutrina constitucional identifica esses fenômenos como gerações de direitos fundamentais, interligadas entre si.

Por ser assim, dentro do paradigma jurídico iniciado pela Lei Constitucional, a legislação infraconstitucional deve estar alinhada aos seus princípios e normas. Assim, oportunamente, interessa investigar a forma como a epilepsia, no âmbito da Previdência Social e da Assistência Social, é vista pelos legisladores ordinários. A epilepsia é uma doença neurológica crônica que pode ser controlada com tratamento específico, contudo, o insucesso no tratamento ainda é alto, assim como a falta de acesso a ele, acontecendo de diversas pessoas com essa deficiência ficarem incapacitadas para o trabalho.

Ademais, pesquisas apontam que, em razão de preconceitos sociais e por falta de políticas públicas, entre outros fatores, os epilépticos enfrentam rejeição do mercado de trabalho, o que colabora para elevadas taxas de desemprego. Desta maneira, alguns indivíduos não conseguem acesso a benefícios previdenciários e assistenciais por causa da ausência de tratamento especial, embora haja viabilidade legal desses 
sujeitos serem alcançados pela cobertura dos citados benefícios, ao passo que, por efeito da rigidez da letra da lei, outros ficam de foram do cuidado do Estado, violando diretamente os valores e disposições constitucionais.

Com o intuito viabilizar esta discussão, importa apresentar os direitos fundamentais, os direitos fundamentais sociais, assim como as disposições gerais sobre a seguridade social contidos na Constituição do Povo. Por conseguinte, outro estudo essencial é a identificação dos benefícios previdenciários do tipo auxílio-doença e aposentadoria por invalidez e como podem ser obtidos. Por fim, como forma de lançar luz sobre estes temas, compara-se os critérios legais para obtenção do auxílio-doença e da aposentadoria por invalidez com os direitos fundamentais e princípios constitucionais e a forma como estas legislações influenciam na qualidade de vida do epiléptico. Feito isso, é provável que se possa apontar os critérios legais que impedem o pleno acesso dos epilépticos ao auxílio-doença e à aposentadoria por invalidez nas situações em que a epilepsia os incapacitam para o trabalho.

Adicionalmente, delineia-se brevemente acerca da metodologia empregada na confecção desta investigação científica: o método é o dedutivo, com uma abordagem qualitativa. Além disto, a fundamentação teórica é essencialmente revisão da literatura pertinente - principalmente livros clássicos e contemporâneos e artigos científicos que exploram os aspectos centrais da construção da qualidade de vida do epiléptico - das legislações específicas e de jurisprudências paradigmas.

\section{DOS DIREITOS E GARANTIAS FUNDAMENTAIS}

A Constituição da República Federativa do Brasil de 1988 (CRFB/88) é mundialmente conhecida pela sua qualidade, pela valorização do ser humano e, consequentemente, pelos direitos fundamentais. Um exemplo disto é o fato de ter sido reservado o seu Título II para os direitos e garantias fundamentais, com seus cinco capítulos voltados para a tutela de bens jurídicos específicos e diferentes entre si, sendo eles: direitos e deveres individuais e coletivos; direitos sociais; nacionalidade; direitos políticos; e partidos políticos. 
Canotilho (2018) compreende ser isto suficiente para ter-se um vislumbre inicial da importância da Lei Maior na redemocratização do Brasil após mais de vinte anos de ditadura militar. A intenção do constituinte originário de romper com as práticas abusivas do passado era tanta que os direitos fundamentais receberam o status de cláusulas pétreas (art. 60, § 4, CRFB/88), ou seja, é vedada a supressão e modificação dos preceitos relacionados aos direitos fundamentais pelos legisladores subsequentes, que são quem detém o poder reformador.

De acordo com Bulos (2018, p. 526), "sem os direitos fundamentais, o homem não vive, não convive, e, em alguns casos, não sobrevive". Ainda consoante ao autor, eles têm características de direitos de defesa, pois viabilizam os pleitos judiciais ou administrativos nos quais o indivíduo visa conter quaisquer invasões dos Poderes Públicos em sua esfera privada. E, de outro lado, a finalidade instrumental das liberdades públicas possibilita que o particular reivindique do Estado: o cumprimento de prestações sociais, proteção contra atos de terceiros e tutela contra discriminações.

É salutar a observação feita pelo mencionado escritor quanto à diferença entre direitos e garantias fundamentais. Pois bem, aqueles são os bens e vantagens previstos na Carta Magna, ao passo que estes, também disciplinados no texto constitucional, são os mecanismos jurídicos que asseguram os exercícios dos direitos elencados na Lei Suprema, limitando os poderes do Estado. Sendo assim, os direitos e garantias fundamentais caminham juntos, até porque o direito, por si só, não tem poder algum se não vier acompanhado de uma garantia, que o tira do papel para materializálo no mundo jurídico (BULOS, 2018).

Por ter os direitos fundamentais alto teor garantista, de preservação da dignidade do ser humano, muito se assemelha aos direitos humanos, podendo, inclusive, serem considerados como sinônimos. Desse modo, Motta (2018), ao lançar luz sobre essa discussão, informa que os direitos humanos são intrínsecos à própria natureza humana, não necessitam de previsão legal, tampouco de considerações espaço-temporais. Sob outra perspectiva, mas ainda dentro da lógica desenvolvida pelo aludido doutrinador, é fato que os direitos fundamentais imprescindem de previsão em documento constitucional. Significa afirmar que o constituinte originário, dos inúmeros direitos humanos, positiva alguns deles, em conformidade com os anseios sociais e o contexto 
histórico. Portanto, o literato pondera serem os direitos fundamentais, por natureza, direitos humanos, mas com caráter relativo, visto variarem a depender dos paradigmas sociais vigentes à época da elaboração do respectivo documento constitucional.

Ademais, considerando que o direito constitucional tal qual se conhece nos dias atuais é produto de mudanças graduais que emergiram do seio da sociedade para dentro das constituições à medida que o tempo se passou e novas necessidades se colocaram como prioridades. Muito bem, as três primeiras gerações de direitos fundamentais estão estreitamente vinculadas aos ideais da Revolução Francesa, a saber: liberdade, igualdade e fraternidade.

Nesse diapasão, sobre a primeira geração de direitos fundamentais, os direitos relacionados às liberdades individuais foram os primeiros a serem positivados, apresentam-se como exemplos as liberdades de crença, de propriedade e de expressão. Pretendia-se, nessa época, impor ao Estado uma postura absenteísta (MENDES; BRANCO, 2017). Estes pensadores, ao apresentarem a segunda geração de direitos fundamentais, ensinam que, tendo a geração anterior posto os direitos sociais de lado para perseguir a liberdade, agora eles se tornaram o seu corolário, de sorte que, nesse momento, cobrava-se a intervenção estatal para a distribuição da justiça social entre os povos. Alguns exemplos desta geração são os direitos à educação, à saúde e à assistência social.

No tocante à terceira geração, Motta (2018) expõe que o seu enfoque se concentrou no ideal de fraternidade, o qual atraiu a atenção dos Poderes Públicos para a proteção dos direitos ao desenvolvimento, à paz e ao meio ambiente. Após, por causa das alterações comportamentais e no estilo de vida humano, Bulos (2018, p. 530) visualiza que a quarta geração de direitos fundamentais objetiva alcançar áreas como "[...] informática, software, biociências, eutanásia, alimentos transgênicos, sucessão dos filhos gerados por inseminação artificial, clonagens [...]". A argumentação do literato avança à quinta geração, cujo objeto primordial é o direito à paz, haja vista a sua indispensabilidade para a manutenção da democracia, que fica abalada em tempos de guerras e insegurança. E mais, Bulos termina tratando acerca da sexta geração de direitos fundamentais, que, a seu ver, aborda os direitos à democracia, à informação e ao pluralismo político. 
Dado o seu prestígio na ordem jurídica, os direitos fundamentais são envoltos por características próprias, que os distinguem e ressaltam a sua soberania. Padilha (2018) infere que eles se caracterizam por serem extrapatrimoniais, universais, inalienáveis, imprescritíveis irrenunciáveis, vinculantes, irrenunciáveis, vinculantes, interdependentes, indivisíveis e históricos.

Destarte, o ponto de partida escolhido pelo constituinte originário brasileiro para o início da normatização dos direitos fundamentais é o caput do art. $5^{\circ}$ da Carta Constitucional, no qual se fala, inicialmente, sobre a inviolabilidade do direito à vida, visando-se, sobretudo, forçar o Estado a garantir um padrão mínimo de vida aos brasileiros e estrangeiros, observando-se a dignidade humana. Esta proteção acaba por incluir, neste, o zelo pelos direitos sociais (educação, saúde, alimentação, trabalho, moradia etc.) (CANOTILHO, 2018).

Contudo, apesar da expressiva quantidade de incisos do aludido artigo dos escritos constitucionais, o seu $\S 2^{\circ}$ deslinda não ser esse rol taxativo, isto é, além dos outros direitos e garantias fundamentais esparsos pela Lex Mater, eles não excluem aqueles decorrentes do regime e dos princípios adotados pela Constituição ou dos tratados internacionais pactuados pela República do Brasil.

Deste modo, não se intenciona, aqui, exaurir esta temática tão rica e cheia de nuances, porém somente proporcionar uma síntese de como se dá a estruturação dos direitos fundamentais na Carta Política de 1988 e, por conseguinte, demonstrar que qualquer sujeito em solo brasileiro é alcançado pelas inovações inauguradas pela Magna Carta, xfrutos de revoluções ao redor do globo, no decorrer dos séculos passados, que guiaram a sua criação.

\section{BREVES NOÇÕES SOBRE OS DIREITOS SOCIAIS E A SEGURIDADE SOCIAL À LUZ DA CONSTITUIÇÃO FEDERAL DE 1988}

$\mathrm{Na}$ Constituição de 1988, reservou-se o art. 6 ao art. 11 para dispor quanto aos direitos sociais, ainda dentro do Título II, ou seja, dentro Dos Direitos e Garantias Fundamentais. Consoante Tavares (2018), o objetivo principal da disponibilização dos direitos sociais é abranger os indivíduos mais vulneráveis, sem prejuízo, contudo, da população em geral. Convenientemente, é oportuna a pergunta elaborada por Mendes 
e Branco (2017): os direitos sociais são tidos como cláusulas pétreas, limitando o poder reformador, visto que o art. 60 , § $4^{\circ}$, IV , da CF/88, faz alusão unicamente aos direitos e garantias individuais?

Bem, de acordo com aqueles pensadores, existem duas correntes que ambicionam responder o aludido questionamento. A primeira nega o status de cláusula pétrea aos direitos sociais, vez que o acima mencionado dispositivo constitucional, propositalmente, deu esta proteção tão somente aos direitos e garantias fundamentais. Ao passo que a segunda corrente argumenta que, guiada pelos Princípios Fundamentais da República (art. $1^{\circ}$ ao art. $4^{\circ}$ ), os direitos sociais participam da medula espinhal da visão de Estado dispensada pela Lei Suprema. Sem eles, é inviável ter-se o princípio da dignidade da pessoa humana como fundamento do Estado Democrático de Direito brasileiro, muito menos cogitar a erradicação da pobreza e da marginalização, bem como a redução das desigualdades sociais e regionais, por exemplo. Adeptos desta última corrente doutrinária, Mendes e Branco (2017) consideram ter havido uma lacuna de formulação no inciso IV do $\S 4^{0}$ do art. 60 , da CRFB/88, ou seja, o constituinte originário teria dito menos do que deveria, razão suficiente para que seja feita uma interpretação expansiva.

A Carta Superior, em seu art. $6^{\circ}$, estabelece que os direitos sociais são "[...] a educação, a saúde, a alimentação, o trabalho, a moradia, o transporte, o lazer, a segurança, a previdência social, a proteção à maternidade e à infância, a assistência aos desamparados [...]", embora nem todos direitos fundamentais sociais estejam elencados no rol do art. 6ㅜㅜ que contém apenas os direitos sociais básicos (SARLET; MARIONI; MITIDIERO, 2018). Assim, nos artigos subsequentes, o enfoque muda e é direcionado ao lançamento das bases do direito do trabalho.

Os escritores retro (2018) apontam duas dimensões dos direitos sociais, negativas e positivas, da mesma forma que acontecem com todos os direitos fundamentais. No desenvolvimento do raciocínio, eles discorrem que a função negativa tem sentido de ser defensiva, ou melhor, com isso cria-se um dever de não interferência em desfavor de terceiros, vedando atos que atentem contra direitos sociais, sem prejudicar, é claro, a sua característica prestacional (positiva) - isto é, ao contrário da 
dimensão negativa, aqui, atrai-se uma intervenção estatal no que toca às prestações materiais, normativas, de criação de políticas públicas, entre outras.

Os direitos sociais, por sua abrangência, comunicam-se com o conteúdo da ordem social, localizada no Título VIII (art. 193 e seguintes), vez que, em conformidade com Tavares (2018), este está inserido naquele. Pois bem, o art. 193 da Constituição Cidadã dispõe que a ordem social brasileira tem como base o primado do trabalho, e seus objetivos são o bem-estar e a justiça social.

Aliás, o citado autor destaca a coincidência entre esta ordem e a ordem econômica, vez que esta também é guiada pela justiça social. Além do mais, é válida a contribuição de Filho (2009) que desenvolveu tese no sentido de que os direitos sociais (aqui incluída a ordem social) possuem íntima correlação com a ordem econômica, pois é impossível que sejam minimamente garantidos quando a economia não vai bem o suficiente.

Nesse cenário, do art. 194 ao art. 204 da CRFB/88, está disciplinada a seguridade social, instituída para velar pelos direitos relativos à saúde, à previdência social e à assistência social. O citado dispositivo constitucional determina que compete ao Poder Público, em observação à legislação específica, a estruturação da seguridade social seguindo os objetivos da universalidade de cobertura e atendimento; a uniformidade e equivalência dos benefícios e serviços às populações urbanas e rurais; seletividade e distributividade na prestação dos benefícios e serviços; a irredutibilidade; a equidade na forma de participação no custeio, do mesmo jeito que a diversidade da base financiamento do sistema; ao final, coloca-se o princípio descentralização da administração e o seu caráter democrático, uma vez que a sua gestão é quadripartite.

Tsutiya (2013) expõe que o recebimento de aposentadoria e salários adequados são peças chaves para que se faça valer o princípio da dignidade humana e os valores do trabalho e da livre iniciativa, por exemplo, contidos no art. $1^{\circ}$, III e IV, da CRFB/88. O pensador, inclusive, aponta que os constituintes aderiram ao modelo europeu de BemEstar Social (Welfare State), que preconiza pelo princípio de caber ao Estado garantir a cada sujeito uma vida digna, com foco principal no bem-estar social, sendo resultado disto a Seguridade Social. 
Sob essa ótica, o escritor demonstra a estreita ligação entre os objetivos fundamentais da República, enumerados no art. $3^{\circ}$ da Lei Fundamental, com o projeto de melhoria de vida da população trabalhadora, inspirado no paradigma de Bem-Estar Social, segundo dito anteriormente. Nesse contexto, o autor explana que a educação é a espinha dorsal de uma sociedade verdadeiramente livre, justa e solidária, sendo acompanhada pelas políticas sociais voltadas para saúde e previdência social. Em suma, Tsutiya (2013, p. 63) reitera que "a Seguridade Social brasileira ampara as pessoas em estado de necessidade social, que não possuem condições mínimas para se manter, independentemente de contribuição [...]", razão pela qual afirma que o princípio da solidariedade é um de seus princípios implícitos.

\section{PREVIDÊNCIA SOCIAL: A FORMA COMO OS BENEFÍCIOS DO TIPO AUXÍLIO- DOENÇA E APOSENTADORIA POR INVALIDEZ PODEM SER OBTIDOS}

Dentro dos ditames da Lei das Leis quanto à Seguridade Social, vale especificar a discussão e, para fins deste trabalho, discorrer especificamente sobre a Previdência Social, prevista constitucionalmente no art. 201 ao art. 202 da CRFB/88 - os quais dispõem acerca do Regime Geral de Previdência Social (RGPS) e do Regime Próprio de Previdência Social (RPPS). Contudo, será abordado, nesta pesquisa, somente o RGPS.

A Carta da República escolheu atribuir à Previdência Social caráter contributivo e de filiação obrigatória, com manutenção do equilíbrio financeiro e atuarial, de outro modo, uma vez que o legislador constituinte instituiu uma rede previdenciária para que estivesse ao alcance da população em geral, se faz necessário que a contribuição seja feita por todos (SANTOS, 2016).

De acordo com o art. 201, I ao V, do Texto Supremo, a cobertura da Previdência Social deve abarcar os seguintes eventos: doença; invalidez; morte; idade avançada; proteção à maternidade, em especial à gestante; proteção contra o desemprego involuntário do trabalhador; salário-família e auxílio reclusão para quem dependa dos segurados de baixa renda; pensão por morte do segurado ao cônjuge ou companheiro e demais dependentes - importando ressaltar a vedação dos valores dos benefícios previdenciários estarem abaixo do salário mínimo. 
Posto isto, Marisa Ferreira (2016) aclara que os indivíduos segurados pela Previdência são pessoas físicas, responsáveis pelas contribuições para o regime previdenciário, a discriminação de quem são estas pessoas está no art. 11 da Lei 8.213/1991 (Plano de Benefícios da Previdência Social - PBPS). Como consequência, ao se filiarem, o que acontece por meio da assinatura da Carteira de Trabalho e Previdência Social (CTPS) pelo empregador - ou ao se inscreverem no Instituto Nacional de Seguro Social (INSS) - ato este mais formal, específico para contribuintes formais ou facultativos.

Ao avançar em seus ensinamentos, a supracitada autora, quando chega na temática do período de carência para obtenção dos benefícios previdenciários, faz alusão ao art. 24 da Lei 8.213/1991, cuja redação diz que o "período de carência é o número mínimo de contribuições mensais indispensáveis para que o beneficiário faça jus ao benefício, consideradas a partir do transcurso do primeiro dia dos meses de suas competências".

Da mesma forma, o art. 26 do Decreto no 3.048/1999, que trouxe o Regulamento da Previdência Social, tem idêntico teor do dispositivo legal apresentado acima. Para Ítalo e Jeane (2016), o pagamento de um determinado número de contribuições mensais garante ao segurado o acesso a benefícios previdenciários. A contribuição, nessa visão, é indispensável para a obtenção dos mesmos, variando, porém, os lapsos temporais mínimos para que o segurado possa requerer o benefício do qual necessite, nos termos do art. 25 da Lei $n^{\circ} 8.213 / 1991$.

Importante se atentar ao que se dá quando um segurado da Previdência, por incapacidade laboral temporária ou permanente, se vê compelido a se socorrer dos benefícios previdenciários do tipo auxílio-doença e aposentadoria por invalidez. Existe previsão específica quanto ao período de carência de ambos, no art. 25 da Lei n. 8.213/1991 e no art. 29, I Decreto n. 3.048/1999, no total de doze meses de contribuições mensais.

Em sintonia com Alencar (2019), o critério para a concessão de benefício de aposentadoria por invalidez e auxílio-doença é unicamente a incapacidade para o trabalho habitual. $O$ autor utiliza o grau da incapacidade laboral e a sua duração para enquadrar o segurado em alguns destes benefícios. Em observância aos ditames da 
legislação específica, ele aponta as seguinte alternativas: a partir do momento em que se constatar a incapacidade total do segurado para quaisquer atividades desempenhadas por ele, o benefício a ser concedido é a aposentadoria por invalidez (art. 42 da Lei n. 8.213/1991 e art. 44, § 3ํ do Decreto n. 3.048/1999). Em contrapartida, nas situações em que o segurado, em razão de doença ou acidente, estiver total e temporariamente incapacitado para o trabalho, por um intervalo de tempo superior a quinze dias consecutivos, será devido a ele o auxílio-doença (art. 59 da Lei n. 8.213/1991).

No entanto, o art. 42 , $\S 2^{\circ}$, e o art. 59 , $\S 1^{\circ}$, da Lei n. 8.213/1991, são categóricos ao vedarem a concessão desses benefícios aos segurados acometidos de doença ou lesão anteriores à filiação ao RGPS, posto que não podem ser invocadas como causa para o benefício, salvo se a incapacidade sobrevier por consequência de seus respectivos agravamentos.

Adicionalmente, há importância em sublinhar que o legislador infraconstitucional trouxe expressa determinação para o tratamento particularizado aos segurados quando da concessão de auxílio-doença e aposentadoria por invalidez, nos casos de acidente, de doença profissional ou do trabalho, assim como nas situações em que o segurado, após a filiação ao RGPS, for identificado com algumas das doenças e afecções pormenorizadas em lista elaborada pelo Ministério da Saúde, devendo ela ser atualizada de três em três anos, com vistas aos critérios de estigma, deformação, mutilação, deficiência ou outro aspecto que the dê especificidade e gravidade que mereçam tratamento particularizado (inteligência retirada do II do art. 26 da Lei 8.213/1991).

Observando isso, o sítio eletrônico do Instituto Nacional do Seguro Social (2018) menciona a regulamentação da lista de isenção de carência feita pela Portaria Interministerial MPAS/MS 2.998/2001, que, por sua vez, elenca as doenças e afecções abaixo: 


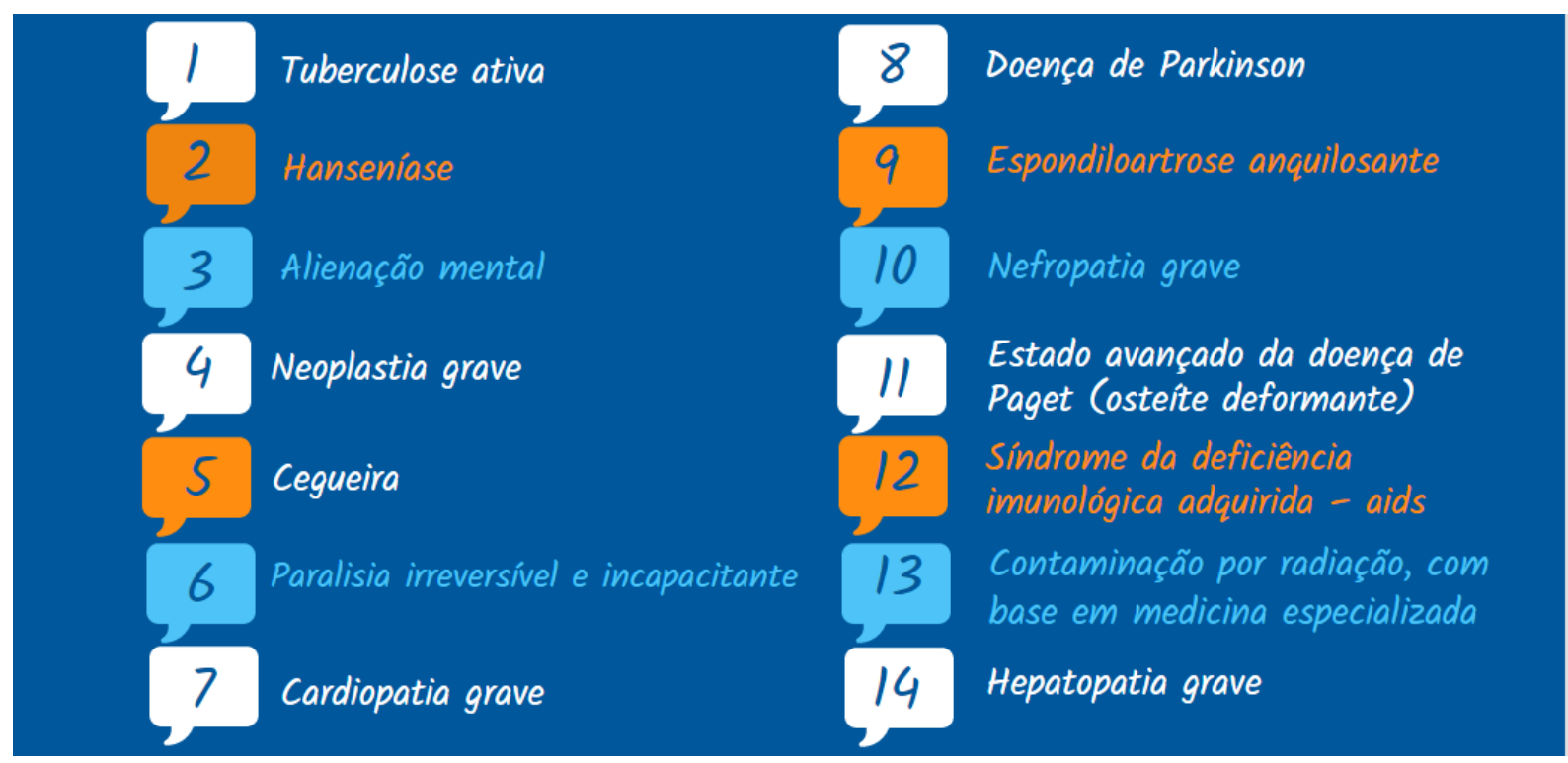

Fonte: https://infograph.venngage.com/templates/recommended.

Nesse enquadramento, 0 art. $2^{\circ}$ da Portaria Interministerial MPAS/MS 2.998/2001 dispõe expressamente que a dispensa de carência para essas doenças e afecções são aplicáveis somente se o segurado for acometido por estes males depois de filiado ao RGPS. Inclusive, antes da elaboração da aludida lista do Ministério da Saúde, havia discriminação de doenças no próprio corpo da Lei n. 8.213/1991, mais especificamente no art. 151, com a seguinte redação:

Art. 151. Até que seja elaborada a lista de doenças mencionada no inciso II do art. 26, independe de carência a concessão de auxíliodoença e de aposentadoria por invalidez ao segurado que, após filiar-se ao RGPS, for acometido das seguintes doenças: tuberculose ativa, hanseníase, alienação mental, esclerose múltipla, hepatopatia grave, neoplasia maligna, cegueira, paralisia irreversível e incapacitante, cardiopatia grave, doença de Parkinson, espondiloartrose anquilosante, nefropatia grave, estado avançado da doença de Paget (osteíte deformante), síndrome da deficiência imunológica adquirida (aids) ou contaminação por radiação, com base em conclusão da medicina especializada.

Repisa-se que os benefícios previdenciários do tipo auxílio-doença e aposentadoria por invalidez são alcançáveis exclusivamente pelos indivíduos segurados pelo RGPS. De outro ponto de vista, aproveita trazer à discussão que a assistência social brasileira, sem considerar a existência de contribuições de caráter 
previdenciário, garante: "[...] um salário mínimo de benefício mensal à pessoa portadora de deficiência e ao idoso que comprovem não possuir meios de prover à própria manutenção ou de tê-la provida por sua família [...]" (CRFB/88, art. 231, V).

Além do mais, para complementar esta explanação, interessa discorrer brevemente sobre o Benefício de Prestação Continuada (BPC), mas focando unicamente na situação do deficiente no âmbito da concessão desse benefício assistencial, consoante a Lei n. 8.742/1993. O BPC é dispensado ao deficiente após a comprovação de cumulativa dos requisitos infra, guiados pela legislação específica e concomitantemente aos apontamentos de Lazzari e Castro (2016):

a) impedimento de longo prazo de natureza física, mental, intelectual ou sensorial (os autores informam que estes impedimentos devem incapacitar para a vida independente e para o trabalho pelo período mínimo de dois anos), o qual, quando diante de uma ou mais barreiras, tenha potencial de obstaculizar a plena e efetiva participação na coletividade em igualdade de condições com os demais (art. 20, § $2^{\circ}$, da Lei n. 8.742/1993, com inteligência dada pela Lei $n^{\circ}$ 13.146/2015);

b) situação de miserabilidade do grupo familiar e da situação de vulnerabilidade;

c) não possuir quaisquer benefícios previdenciários ou de outro regime, ressalvados a assistência médica e a pensão especial indenizatória;

d) inscrição no Cadastro de Pessoas Físicas (CPF) e no Cadastro Único para Programas Sociais do Governo Federal (CadÚnico) (condição imposta pelo Decreto n. 8.805, de 07.07.2016).

Compreendida a cobertura dada pela Assistência Social aos idosos ou deficientes que, porventura, não foram alcançados pela Previdência Social, percebe-se que tanto o legislador constituinte quanto o infraconstitucional visualizaram a inclusão dos trabalhadores e dos sujeitos que eventualmente não são segurados pela previdência no seio da Seguridade Social, uma vez que a saúde, outra ramificação deste, também é distribuída a todos através do Sistema Único de Saúde (SUS). 


\section{CONFLITOS: O DIÁLOGO ENTRE A EPILEPSIA E AS REGRAS PARA OBTENÇÃO DE AUXÍLIO-DOENÇA E APOSENTADORIA POR INVALIDEZ}

A epilepsia é "[...] uma síndrome neurológica paroxística com diversidade clínica e prognóstica, de acometimento de $0,5-1,0 \%$ da população geral" (GOMES, 2009, p. 2). Ainda segundo a autora, embora não seja regra, a epilepsia, quando intimamente associada à déficits degenerativos e à falta de controle das crises epilépticas, resulta em incapacidade laborativa - entendendo-se por isto a inviabilidade temporária ou definitiva do desempenho da profissão ou de qualquer outra atividade.

Apesar de existirem significativos avanços no controle das crises epilépticas cerca de $70 \%$ dos pacientes epilépticos têm suas crises controladas pelo tratamento clínico-farmacológico (GIROLINETO, 2009) - no trato da doença e, especialmente, na democratização do acesso à saúde no Brasil, os epilépticos continuam com baixos índices de qualidade de vida, isto porque, segundo pesquisas como a de Salgado e Souza (2002, p. 2), considera-se que a área mais afetada pela epilepsia é a do trabalho, acompanhada de "[...] lazer, saúde emocional, escola, saúde física, relacionamento sociais".

Nesse cenário, parte-se da premissa de que a empregabilidade reflete decisivamente na qualidade de vida de um epiléptico (ALONSO et al, 2009), influenciando positivamente o tratamento da epilepsia, razão pela qual estar empregado é, em regra, crucial para o seu progresso. Todavia, no geral, a sociedade brasileira enfrenta o problema de altas taxas de desemprego, mas, em visão micro, aqueles acometidos de doenças crônicas são ainda mais prejudicados (GOMES, 2000).

Magalhães et al (2004) afirmam que a alta prevalência da epilepsia fez dela um problema de saúde pública, vez que a ausência de tratamento de um epiléptico requer hospitalizações frequentes devido às convulsões e traumas ocasionados pelas crises ou pela reabilitação. Os pesquisadores ainda apontam que o epiléptico sem tratamento se torna um fardo para seus familiares e para o Estado.

Diante dos volumosos dados que indicam os danos ocasionados pela epilepsia na vida de quem por ela é acometido - como as dificuldades de ampliação do tratamento dessa doença nos municípios brasileiros (MAGALHÃES et al, 2004), o alto índice de desemprego desses deficientes (GOMES, 2000) e os óbices no tocante ao 
controle das crises epilépticas (GIROLINETO, 2009) - a pergunta que se faz é sobre como essa população é amparada pela sociedade e pelo Poder Público. Existe espaço especial para eles na Previdência Social ou na Assistência Social?

São proveitosos os escritos de Carvalho (BRASIL, 2011), consultor legislativo da área $\mathrm{XVI}$, em seu parecer jurídico que trata a respeito da viabilidade de serem os epilépticos, para efeito de lei, tidos como deficientes. Ciente da preponderância e da quantidade de epilépticos sem tratamento, frisa que essa doença deve ser pauta prioritária no cotidiano das autoridades, mas, de outro modo, rechaça a ideia de considerar os epilépticos como deficientes, por entender não ser tecnicamente correto. O citado consultor legislativo, ao afirmar isso, pauta-se na alegação de que há diversos casos de sucesso de pacientes que controlam perfeitamente seus respectivos quadros clínicos, muitos deles sem ao menos laçarem mão de tratamento farmacológico.

Em contrapartida, o Senador Paulo Paim (PT-RS) propôs o Projeto de Lei $\mathrm{n}$. 7797/2010, visando à alteração do art. 151 da Lei n. 8.213/1991 para dispensar o prazo de carência para concessão de benefícios previdenciários do tipo auxílio-doença e aposentadoria por invalidez aos portadores de lúpus e epilepsia. A Comissão de Constituição e Justiça da Câmara dos Deputados aprovou o Projeto - assim, após a análise em caráter conclusivo, ele poderá seguir para sanção presidencial (BRASIL, 2018).

Em sua Justificação, o Senador arguiu que a lúpus e a epilepsia têm potencial para incapacitar o paciente para o trabalho, razão pela qual entende pela obrigatoriedade da aposentadoria por invalidez nestes casos. O parlamentar visualiza que, hodiernamente, existe uma lacuna na legislação que impede o pleno acesso dos epilépticos e pessoas acometidas por lúpus à Previdência Social.

Diante da atual sistemática das leis previdenciárias, aponta-se que os critérios para concessão de auxílio-doença e aposentadoria por invalidez, em regra, estendemse somente aos segurados, quando dentro do período mínimo de carência de doze meses, salvo se o indivíduo se encaixar nas hipóteses de dispensa de carência, por causa de doença e afecções graves discriminadas na lista elaborada pelo Ministério da Saúde. Não obstante, logicamente, sabe-se que um dos meios mais comuns para ser segurado do RGPS é através do trabalho formal. 
Porém, a péssima absorção dos epilépticos pelo mercado de trabalho ainda persiste, seja por causa da rigidez das leis, que restringem a empregabilidade daqueles que padecem de epilepsia, sem as devidas reservas (o que é necessário somente para as profissões nas quais os epilépticos poderiam representar risco para a sua vida e da de terceiros) (SARMENTO; GOMEZ, 2000), ou pela consequência direta dos estigmas sociais, dos preconceitos, do desconhecimento acerca dessa doença, o que desemboca em exclusão de atividades profissionais, acadêmicas e sociais (ARANGO et al, 2018).

Isto posto, observados os baixos índices de empregabilidade dos epilépticos, essa realidade fática se coloca como limitadora do acesso aos benefícios previdenciários pelos epilépticos (em especial o auxílio-doença e aposentadoria por invalidez), sendo estes restringidos apenas à ínfima parcela das pessoas com deficiência que alcançam a qualidade de segurado pela Previdência Social.

Igualmente, é importante mostrar que o acesso ao BPC, da Assistência Social, é uma possível alternativa para as pessoas que encontram impedimentos de acesso aos benefícios previdenciários explicitados em momento anterior. Destaca-se, aliás, que os requisitos para obtenção do BPC também devem ser observados. O art. 20 , § $3^{\circ}$, da Lei 8.742/1993 (com a nova redação dada pela Lei 13.981/2020), estabelece como requisito para obtenção do BPC a comprovação de renda familiar em quantia inferior a $1 / 2$ do salário mínimo.

Ainda sobre o BPC, coaduna com a exposição acima duas súmulas da Turma Nacional de Uniformização dos Juizados Especiais Federais (TNU). O conteúdo da súmula 80 (2015) evidencia a necessidade de valoração da realidade fática da pessoa com deficiência (contextos como os fatores ambientais, sociais, econômicos e pessoais), a fim de, por meio de avaliação social, se apurar os impactos na participação desse indivíduo na sociedade.

Outra importante pacificação do TNU decorre da súmula 78 (2014), ela, por sua vez, trata especialmente no que tange os critérios para averiguação das "condições pessoais, sociais, econômicas e culturais" do requerente de benefício portador do vírus HIV, para viabilizar a análise da incapacidade laborativa em sentido amplo. Ainda sob essa perspectiva, a citada súmula delineou com clareza que o sujeito com vírus HIV 
está sujeito a uma elevada estigmatização social da doença, aspecto este que deve ser considerado quando desta avaliação.

Esse raciocínio inovador conversa diretamente com a situação dos epilépticos, porque, como bem demonstrado no desenvolvimento deste trabalho, resta claro que a epilepsia traz consigo, da mesma forma que o vírus HIV, um alto teor de estigmatização social, de modo que também se faz imprescindível que a observação da incapacidade laborativa do epiléptico se dê nos termos da súmula 78 do TNU, tanto em se tratando de Previdência Social quanto de Assistência Social.

\section{CONCLUSÃO}

Observa-se que os parâmetros legais para 0 acesso aos benefícios previdenciários do tipo auxílio-doença e aposentadoria por invalidez alcançam os epilépticos, desde que se satisfaça todos os requisitos legais. Não obstante, é perceptível que a falta de tratamento especial aos epilépticos tem poder de barrar a concessão desses benefícios a quem realmente necessita.

Considerando que, apesar de não ser regra, a epilepsia pode ocasionar incapacidade laborativa, e somado o fato da péssima absorção dos epilépticos pelo mercado de trabalho aliado à estigmatização do epiléptico, fica nítido que a inexigibilidade de período de carência para os epilépticos parece ser uma medida razoável, capaz de zelar pela dignidade humana dessa parcela da população.

Apesar disso, possíveis alterações devem ser precedidas de amplo debate e análises de impactos orçamentários, com estudos que também abarquem os critérios sociais, pessoais, econômicos e culturais dos indivíduos com epilepsia, seguindo o fio deixado pelo TNU na súmula 78.

Estudiosos apontam que, no Brasil, a epilepsia é um problema de saúde pública, exigindo do Estado articulações para proporcionar tratamento de saúde adequados, os quais se dão na esfera do SUS com relativa eficácia. Mas não só isso, a disponibilização de cuidados com a saúde dos epilépticos não isenta o Poder Público do dever de atender os demais aspectos inerentes à vida em sociedade, como alimentação, lazer, entre outros. 
Em suma, uma vez que uma pessoa com deficiência se torna incapaz de proporcionar a si mesma e a seus dependentes uma vida minimamente digna, ainda mais se esse fenômeno ocorrer numa escala gigantesca, isso se torna um problema do Estado e da sociedade. De maneira que aquele é diretamente obrigado pela Carta Cidadã de zelar e garantir os direitos fundamentais de seus cidadãos.

\section{REFERÊNCIAS}

ALENCAR, Hermes Arrais. Direito previdenciário para concursos. 6aㅡ ed. São Paulo: Saraiva Educação, 2019. [Minha Biblioteca].

ALONSO, Neide Barreira et al. Employment and quality of life in mesial temporal lobe epilepsy with hippocampal sclerosis: is there a change after surgical treatment?. Journal of Epilepsy and Clinical Neurophysiology, Porto Alegre, v. 15, n. 2, p. 89-93, jun. 2009. Disponível em: http://dx.doi.org/10.1590/S1676-26492009000200008. Acesso em: 15 nov. 2019.

ALONSO, Neide Barreira et al. Sintomas depressivos e qualidade de vida em indivíduos com epilepsia por esclerose mesial temporal. Journal of Epilepsy and Clinical Neurophysiology, Porto Alegre, v. 11, n. 3, p. 117-122, 2005. Disponível em: http://dx.doi.org/10.1590/S1676-26492005000300009. Acesso em: 15 nov. 2019.

ARANGO, Amparo Ponce- et al. Discriminación laboral en México a las personas com epilepsia. Revista CONAMED, v. 24, n.1 p. 46, mar. 2019. Disponível em: https://web.b.ebscohost.com/abstract?direct=true\&profile=ehost\&scope=site\&authtype= crawler\&jrnl=14056704\&AN=137302234\&h=d37ijMUgAXc7wnBhK5hBY3j9LYzmRym8 M\%2f5V38FNEsTQswi8f\%2fyhcoPjl1HU535cjhk0XMK\%2fO9\%2fOc8AWWEyvvg\%3d\% $3 \mathrm{~d} \& \mathrm{crl}=\mathrm{c} \&$ resultNs=AdminWebAuth\&resultLocal=ErrCrINotAuth\&crlhashurl=login. aspx\% 3fdirect\%3dtrue\%26profile\%3dehost\%26scope\%3dsite\%26authtype\%3dcrawler\%26jrnl \%3d14056704\%26AN\%3d137302234. Acesso em: 15 nov. 2019.

BULOS, Uadi Lammêgo. Curso de direito constitucional. 11르 ed. São Paulo: Saraiva Educação, 2018.

BRASIL. Câmara dos Deputados. Câmara aprova dispensa de carência para benefícios do INSS a portador de lúpus ou epilepsia: proposta segue para sanção presidencial. Brasília: Câmara dos Deputados, 07 nov. 2018. Disponível em: https://www.camara.leg.br/noticias/547477-camara-aprova-dispensa-de-carencia-parabeneficios-do-inss-a-portador-de-lupus-ou-epilepsia/. Acesso em: 13 nov. 2019.

. Câmara dos Deputados. Consultoria Legislativa. Epilepsia: deficiência?. Brasília: Câmara dos Deputados, out. 2011. Disponível em: 
https://www2.camara.leg.br/atividade-legislativa/estudos-e-notas-tecnicas/publicacoesda-consultoria-legislativa/areas-da-conle/tema19/2011 13538.pdf. Acesso em: 13 nov. 2019.

. Câmara dos Deputados. Coordenação de Comissões Permanentes. Documentos avulsos [Comissão de seguridade social e família]. Brasília: Câmara dos Deputados, 2012. Disponível em: https://www.camara.leg.br/proposicoesWeb/fichadetramitacao?idProposicao=485247. Acesso em: 13 nov. 2019.

. [Constituição (1988)]. Constituição da República Federativa do Brasil de 1988. Brasília, DF: Presidência da República, [1988]. Disponível em: http://www.planalto.gov.br/ccivil_03/constituicao/constituicaocompilado.htm. Acesso em: 20 out. de 2019.

. Decreto no 3.048, de 6 de maio de 1999. Aprova o Regulamento da Previdência Social, e dá outras providências. Brasília, DF: Presidência da República, [1999]. Disponível em: http://www.planalto.gov.br/ccivil_03/decreto/d3048.htm. Acesso em: 15 nov. 2019.

. Decreto $\mathrm{n}^{\circ}$ 8.805, de 7 de julho de 2016. Altera o Regulamento do Benefício de Prestação Continuada , aprovado pelo Decreto oㅜ 6.214, de 26 de setembro de 2007. Brasília, DF: Presidência da República, [2016]. Disponível em: http://www.planalto.gov.br/ccivil_03/_ato2015-2018/2016/decreto/d8805.htm. Acesso em: 15 nov. 2019.

Lei $\mathbf{n}^{\circ}$ 8.742, de 7 de dezembro de 1993. Dispõe sobre a organização da Assistência Social e dá outras providências. Brasília, DF: Presidência da República, [1993]. Disponível em: http://www.planalto.gov.br/ccivil_03/LEIS/L8742.htm. Acesso em: 15 nov. 2019.

. Lei $\mathbf{n}^{\circ}$ 13.981, de 23 de março de 2020. Altera a Lei no 8.742, de 7 de dezembro de 1993 (Lei Orgânica da Assistência Social), para elevar o limite de renda familiar per capita para fins de concessão do benefício de prestação continuada. Brasília, DF: Senado Federal, [2020]. Disponível em: http://www.planalto.gov.br/ccivil_03/_ato2019-2022/2020/lei/L13981.htm. Acesso em: 05 maio 2020.

. Conselho da Justiça Federal. Súmula 78. Comprovado que o requerente de benefício é portador do vírus HIV, cabe ao julgador verificar as condições pessoais, sociais, econômicas e culturais, de forma a analisar a incapacidade em sentido amplo, em face da elevada estigmatização social da doença. Turma Nacional de Uniformização dos Juizados Especiais Federais, [2014]. Disponível em: https://www.cjf.jus.br/phpdoc/virtus/sumula.php?nsul=78. Acesso em: 02 jan. 2020. 
BRASIL. Conselho da Justiça Federal. Súmula 80. Nos pedidos de benefício de prestação continuada (LOAS), tendo em vista o advento da Lei 12.470/11, para adequada valoração dos fatores ambientais, sociais, econômicos e pessoais que impactam na participação da pessoa com deficiência na sociedade, é necessária a realização de avaliação social por assistente social ou outras providências aptas a revelar a efetiva condição vivida no meio social pelo requerente. Turma Nacional de Uniformização dos Juizados Especiais Federais, [2015]. Disponível em:

https://www.cjf.jus.br/phpdoc/virtus/sumula.php?nsul=80. Acesso em: 02 jan. 2020.

CANOTILHO, José Joaquim Gomes et al. Comentários à Constituição do Brasil. $2^{\mathrm{a}}$ ed. São Paulo: Saraiva Educação, 2018. [Minha Biblioteca].

EDUARDO, Ítalo Romano; EDUARDO, Jeane Tavares Aragão. Curso de direito previdenciário: teoria, jurisprudência e questões. $12^{\underline{a}}$ ed. Rio de Janeiro: Forense; São Paulo: Método, 2019. [Minha Biblioteca].

FERREIRA FILHO, Manoel Gonçalves. Curso de direito constitucional. 35aㅡ ed. São Paulo: Saraiva, 2009.

GIROLINETO, Beatriz Maria Pereira. A intercambialidade entre equivalentes terapêuticos da lamotrigina: avaliação clínica e laboratorial dos pacientes portadores de epilepsia refratária [Mestrado]. Biblioteca Digital USP, teses e dissertações, Ribeirão Preto - SP, 27 nov. 2009. Disponível em:

https://teses.usp.br/teses/disponiveis/60/60137/tde-13122009-200659/pt-br.php. Acesso em: 15 nov. 2019.

GOMES, Marleide da Mota. Client with epilepsy in a work brazilian rehabilition center. Arq. Neuro-Psiquiatr., São Paulo, v. 58, n. 2A, p. 227-232, jun. 200. Disponível em: http://dx.doi.org/10.1590/S0004-282X2000000200004. Acesso em: 15 nov. 2019.

GOMES, Marleide da Mota. Epilepsia e incapacidade laborativa. Journal of Epilepsy and Clinical Neurophysiology, Porto Alegre, v. 15, n. 3, p. 130-134, set. 2009. Disponível em: http://dx.doi.org/10.1590/S1676-26492009000300007. Acesso em: 15 nov. 2019.

INSTITUTO NACIONAL DO SEGURO SOCIAL. Carência. Instituto Nacional de do Seguro Social, 16 maio 2017. Disponível em:

https://www.inss.gov.br/orientacoes/carencia/. Acesso em: 12 de nov. de 2019.

LAZZARI, João Batista; CASTRO, Carlos Alberto Pereira de. Direito previdenciário. Rio de Janeiro: Forense, 2016.

MENDES, Gilmar Feirra; BRANCO, Paulo Gustavo Gonet. Curso de direito constitucional. 12 ${ }^{\mathrm{a}}$ ed. São Paulo: Saraiva, 2017 [Minha Biblioteca]. 
MOTTA, Sylvio. Direito constitucional: teoria, jurisprudência e questões. $27^{a} \stackrel{a}{ }$ ed. São Paulo: Editora Método, 2018. [Minha Biblioteca].

NORONHA, Ana Lúcia Andrade et al. Assessment of the epilepsy treatment gap in two cities of south-east of Brazil. Arq. Neuro-Psiquiatr, São Paulo, v. 62, n. 3b, p. 761-763, sep. 2004. Disponível em: http://www.scielo.br/scielo.php?script=sci arttext\&pid=S0004282X2004000500003. Acesso em: 13 nov. 2019.

PADILHA, Rodrigo. Direito constitucional. 5. ed. São Paulo: Editora Forense, 2018. [Minha Biblioteca].

SALGADO, Priscila Camile Barioni; SOUZA, Elisabete Abib Pedroso de. Impacto da epilepsia no trabalho: avaliação da qualidade de vida. Arq. Neuro-Psiquiatr., São Paulo, v. 60, n. 2B, p. 442-445, jun. 2002. Disponível em: http://dx.doi.org/10.1590/S0004-282X2002000300019. Acesso em: 15 nov. 2019.

SANTOS, Marisa Ferreira dos. Direito previdenciário. 12ª ed. São Paulo: Saraiva, 2016 - (Coleção sinopses jurídicas; v. 25). [Minha Biblioteca].

SARLET, Ingo Wolfgang; MARINONI, Luiz Guilherme; MITIDIERO, Daniel. Curso de direito constitucional. $7^{a}$ ed. São Paulo: Saraiva Educação, 2018. [Minha Biblioteca].

SARMENTO, Maria Rosa Silva. GOMEZ, Carlos Minayo-. A epilepsia, o epiléptico e o trabalho: relações conflitantes. Cad. Saúde Pública, Rio de Janeiro, v. 16, n. 1, p. 183193, jan./mar. 2000. Disponível em: http://dx.doi.org/10.1590/S0102311X2000000100019. Acesso em: 15 nov. 2019.

SECRETARIA DE PREVIDÊNCIA. Portaria interministerial MPAS/MS n' 2.998, de 23 de agosto de 2001. Disponível em: http://sislex.previdencia.gov.br/paginas/65/MPASMS/2001/2998.htm. Acesso em: 12 nov. 2019.

TAVARES, André Ramos. Curso de direito constitucional. 16ª ed. São Paulo: Saraiva Educação, 2018. [Minha Biblioteca].

TSUTIYA, Augusto Massayuki. Curso de direito da seguridade social. $4^{a}$ ed. São Paulo: Saraiva, 2013. [Minha Biblioteca]. 